\title{
Pengaruh Kepemimpinan Transformasional dan Iklim Organisasi terhadap Perilaku Kerja Inovatif pada Karyawan Industri Perhotelan
}

\author{
PUSPITA SANDYA MAHARDIKA \& DEWI SYARIFAH* \\ Departemen Psikologi Industri dan Organisasi, Fakultas Psikologi Universitas Airlangga
}

\begin{abstract}
ABSTRAK
Penelitian ini bertujuan untuk mengetahui pengaruh kepemimpinan transformasional dan iklim organisasi terhadap perilaku kerja inovatif. Sampel penelitian ini adalah 73 karyawan yang bekerja di hotel-hotel Indonesia, yang dikunpulkan melalui survei daring. Variabel kepemimpinan transformasional diukur menggunakan skala Transformational Leadership yang dikembangkan oleh Robbins, variabel iklim organisasi diukur menggunakan skala Organizational Climate Measure (OCM) yang dikembangkan oleh Patterson dan variabel perilaku kerja inovatif diukur menggunakan skala Innovative Work Behavior yang dikembangkan oleh Janssen. Data dianalisis menggunakan simple linear regression dan multiple linear regression. Hasil penelitian menunjukkan bahwa variabel kepemimpinan transformasional dan iklim organisasi tidak memiliki pengaruh yang signifikan terhadap perilaku kerja inovatif.
\end{abstract}

Kata kunci: hotel, iklim organisasi, kepemimpinan transformasional, perilaku kerja inovatif

\begin{abstract}
Innovative behavior is needed to maintain the existence of the hotel. This study aims to determine the effect of transformational leadership and organizational climate on innovative work behavior. The sample of this research is 73 employees who work in hotels in Indonesia, which were collected through online surveys. Transformational leadership variables are measured using the transformational leadership scale developed by Robbins organizational climate variables are measured using the Organizational Climate Measure (OCM) scale developed by Patterson, et al and innovative work behavior variables are measured using the innovative work behavior scale developed by Janssen. Data were analyzed using simple linear regression and multiple linear regression. The results showed that transformational leadership and organizational climate did not have a significant effect on innovative work behavior.
\end{abstract}

Keywords: hotel, innovative work behavior, organizational climate, tranfosmasional leadership

Buletin Penelitian Psikologi dan Kesehatan Mental (BRPKM), 2021, Vol. 1(1), 387-395

*Alamat korespondensi: Fakultas Psikologi Universitas Airlangga, Kampus B Universitas Airlangga Jalan Airlangga 4-6 Surabaya 60286. Surel: dewi.syarifah@psikologi.unair.ac.id

Naskah ini merupakan naskah dengan akses terbuka dibawah ketentuan the Creative Common Attribution License (CC-BY-4.0) (http://creativecommons.org/licenses/by/4.0), sehingga penggunaan, distribusi, reproduksi dalam media apapun atas artikel ini tidak dibatasi, selama sumber aslinya disitir dengan baik. 


\section{PEN D A H U L U A N}

Industri pariwisata telah menjadi sektor yang paling banyak diminati di Indonesia, karena memiliki banyak keunggulan serta menjadi salah satu penyumbang peningkatan ekonomi terbesar untuk Indonesia. Bisnis pariwisata di Indonesia dinilai cukup potensial, mengingat Indonesia memiliki banyak sekali keindahan alam, keragaman budaya, serta keunikan yang jarang dimiliki oleh negara lain. Semua potensi tersebut dapat menjadi modal industri pariwisata di Indonesia. Berdasarkan laman Dinas Pariwisata Indonesia, pada industri pariwisata terdapat beberapa ruang lingkup yaitu bidang restoran, penginapan, pelayanan perjalanan, transportasi pengembangan daerah tujuan wisata, fasilitas rekreasi dan atraksi wisata. Dari beberapa ruang lingkup tersebut industri hotel merupakan aspek yang dinilai paling penting, sebab hotel sebagai sarana akomodasi umum untuk membantu wisatawan yang sedang berkunjung untuk berwisata dengan jasa penginapan yang disediakan.

Menurut Badan Pusat Statistik (BPS) jumlah hotel di Indonesia sampai pada tahun 2018 berjumlah 3,314. Jumlah hotel ini tidak sedikit sehingga mampu menciptakan persaingan antar hotel. Berdasarkan penelitian yang dilakukan oleh Astuti, dkk (2019), selain pertambahan jumlah hotel di Indonesia yang semakin meningkat, ditambah dengan biaya transportasi yang semakin murah membuat industri pariwisata dan perhotelan di Indonesia terus membutuhkan tenaga kerja yang terampil dan handal. Kualitas jasa menjadi semakin dominan, ditunjukkan dengan persaingan yang semakin kompetitif yang dapat mendorong konsumen terpuaskan atas apa yang sudah dibayar Astuti, dkk (2019). Adanya persaingan global menjadikan tantangan bagi setiap perusahaan untuk terus melakukan upaya serta menerapkan strategi agar mampu bertahan dan memenangkan persaingan yang kompetitif Astuti, dkk (2019).

Selain itu, diperlukan juga adanya inovasi dalam perencanaan yang strategis agar hotel-hotel di Indonesia mampu bertahan dalam persaingan. Adanya inovasi yang baru dan berbeda merupakan hal yang efektif dan mampu mendorong sebuah penciptaan sebuah nilai dan daya saing (Ikeda \& Marshall, (2016). Inovasi merupakan hal yang penting dalam pengembangan posisi perusahaan dalam pasar. Industri perhotelan harus memahami keinginan pelanggan, agar hotel dapat memberikan manfaat kepada pelanggan yang ingin menggunakan jasa hotel serta memahami keuntungan yang dapat diperoleh dari sebuah inovasi (Hargadon, 2015).

Menurut De Jong \& Hartog (2008), perilaku kerja inovatif merupakan eksplorasi peluang dan generalisasi dari ide-ide baru yaitu perilaku yang berhubungan dengan kreativitas. Perilaku kerja inovatif dapat mencakup perilaku yang diarahkan menuju penerapan perubahan, penerapan pengetahuan baru atau peningkatan proses kinerja pribadi dan/atau bisnis yang berorientasi pada implementasi dari ide tersebut kedalam pekerjaannya (Jong \& Hartog, 2008). Inovasi dalam dunia kerja dinilai dengan pencapaian hasil hingga pembaharuan yang absolut dan besar (Rogers, 1998).

Menurut Janssen (2000) merupakan penciptaan yang disengaja, pengenalan dan penerapan ide-ide baru dalam peran kerja, kelompok atau organisasi, yang bertujuan untuk mendapatkan manfaat dari peran kerja, kelompok ataupun organisasi. Inovasi memiliki keuntungan yang mampu memberikan fungsi organisasi dan manfaat sosial-psikologis dengan lebih baik bagi pekerja individu atau kelompok individu (Janssen, 2000). Menurut Janssen (2000) terdapat tiga tahapan dalam inovasi, yaitu Idea Generalization, Idea Promoting dan Idea Realization. Tahapan-tahapan tersebut merupakan tahapan dimana individu mulai menemukan inovasinya, kemudian mencari dukungan untuk memperkuat inovasi tersebut dan yang terakhir bagaimana individu tersebut merealisasikan inovasi yang sudah dicetuskan sebelumnya (Janssen, 2000). 
Berdasarkan Global Innovation Index (GII), Indonesia memiliki skor 29,8 yaitu pada peringkat 85 dari 129 negara di dunia. Dalam tingkat regional ASEAN, Indonesia berada pada urutan kedua terendah. Hal ini menandakan bahwa masih rendahnya inovasi pada perusahaan-perusahaan di Indonesia.

Keberhasilan suatu organisasi atau perusahaan juga bertumpu pada bagaimana pemimpin mendorong serta memotivasi anggotanya untuk berpikir inovatif dan kreatif (Webber, 2002). Menurut Li dan Zheng (2014) terdapat beberapa faktor yang memengaruhi perilaku kerja inovatif seorang karyawan, yaitu faktor individual dan faktor organisasional. Masing-masing faktor tersebut dibedakan lagi menjadi beberapa faktor dimana dalam faktor individual terdapat komitmen organisasi dan modal psikologis. Sedangkan dalam faktor organisasional didalamnya terdapat iklim inovatif organisasi, kepemimpinan dan modal sosial.

Odoardi, dkk (2015) menyebutkan bahwa aspek yang memainkan peranan penting dalam membangun kreativitas dan inovasi di suatu organisasi adalah pemimpinnya. Bass (1990) membagi kepemimpinan menjadi dua tipe yaitu kepemimpinan transformasional dan kepemimpinan transaksional.

Beberapa ahli menyatakan bahwa kepemimpinan transformasional merupakan tipe kepemimpinan yang cocok untuk mendorong perilaku inovatif karyawan dibandingkan tipe kepemimpinan transaksional. Seperti penelitian yang dilakukan oleh Nusair, dkk (2012) yang menyebutkan bahwa tipe kepemimpinan transformasional mampu mendorong perilaku inovatif anggotanya. Kepemimpinan transformasional sendiri adalah bentuk kepemimpinan dimana pemimpin menggerakkan anggotanya untuk dapat menemukan ketertarikan dalam dirinya dan mendorong anggotanya untuk mencapai tingkat kedewasaan serta kondisi ideal dalam hal pencapaian, aktualisasi diri dan keberadaan masingmasing anggota, organisasi dan masyarakat (Cho \& Danserau, 2010)

Selanjutnya dalam faktor organisasional juga terdapat iklim organisasi yang turut memengaruhi perilaku inovatif karyawan selain kepemimpinan transformasional (West \& Farr, 1898). Iklim organisasi didefinisikan sebagai gambaran pada karyawan berdasarkan pengalaman pada organisasinya dimana dalam hal ini iklim organisasi menunjukkan persepsi karyawan terhadap aturan, praktek serta prosedur kerja yang mendukung kreativitas, inovasi, keselamatan pelayanan dalam lingkungan organisasi (Patterson, et al., 2005).

Berdasarkan keseluruhan hal yang telah dipaparkan di atas, disimpulkan bahwa industri perhotelan di Indonesia memerlukan inovasi untuk terus memberikan pelayanan yang terbaik bagi konsumen. Untuk meningkatkan inovasi, diperlukan faktor kepemimpinan transformasional dan iklim organisasi yang mendorong perilaku kerja inovatif karyawannya. Hipotesis pada penelitian ini adalah adanya pengaruh kepemimpinan transformasional dan iklim organisasi terhadap perilaku kerja inovatif karyawan.

\section{Desain Penelitian}

\section{E T O D E}

Tipe penelitian yang digunakan adalah tipe penelitian kuantitatif. Penelitian kuantitatif merupakan metode penelitian yang menggunakan data dalam bentuk angka numerikal kemudian data tersebut diolah dengan menggunakan statistik (Azwar, 2004). Menurut Azwar (2004) penelitian dengan pendekatan kuantitatif pada dasarnya dilakukan pada penelitian inferensial, dimana untuk pengujian hipotesis dan pembuatan kesimpulan dari hasil uji hipotesis nantinya akan didapatkan signifikansi hubungan antar variabel yang akan diteliti (Azwar, 2004) 
Berdasarkan tujuan penelitiannya, tipe penelitian yang digunakan adalah explanatory research dimana tipe penelitian ini akan menjelaskan pengaruh ataupun hubungan antara variabel-variabel penelitian dengan tujuan untuk menguji hipotesis yang telah dibuat dari suatu teori yang menjelaskan variabel penelitian tersebut (Neuman, 2007). Terdapat 3 teknik dalam pengumpulan data kuantitatif yaitu teknik eksperimen, survei dan non-reactive research (Neuman, 2007).

Teknik pengumpulan data yang digunakan pada penelitian ini menggunakan teknik survei, dimana penulis tidak memanipulasi situasi atau kondisi yang ada untuk mengetahui reaksi subjek, namun hanya untuk mengumpulkan jawaban yang diberikan oleh subjek. Teknik survei dilakukan dengan cara menyebarkan kuesioner tertulis pada beberapa subjek tanpa adanya pengkondisian atau perbedaan perlakuan terhadap subjek (Neuman, 2007). Dalam penelitian ini, peneliti bertujuan untuk menguji ada atau tidaknya pengaruh kepemimpinan transformasional dan iklim organisasi terhadap perilaku kerja inovatif pada karyawan yang bekerja di industri perhotelan di Indonesia.

\section{Partisipan}

Pada penelitian ini, partisipan merupakan karyawan yang bekerja di hotel dengan kriteria memiliki atasan, berusia pada rentang 19 sampai 48 tahun, dan pendidikan minimal SMA/SMK. Teknik sampling yang digunakan adalah purposive sampling termasuk di dalamnya non-probability sampling dimana teknik sampling ini biasanya digunakan ketika terdapat keterbatasan pengetahuan mengenai besarnya populasi penelitian (Neuman, 2007). Peneliti menggunakan metode ini dengan pertimbangan jangka waktu yang terbatas dan kemudahan peneliti dalam pengumpulan data.

Dalam menentukan jumlah sampel yang digunakan, peneliti menggunakan aplikasi Gpower 3.1. Teknik dalam Gpower yang digunakan adalah a priori power analysis berjenis linear multiple regression: Fixed model, $R^{2}$ deviation from zero. Teknik tersebut digunakan untuk mengetahui ukuran sampel yang diperlukan, effect size yang diperlukan sebesar 0.15 dengan statistical power $80 \%$ dan alpha sebesar $5 \%$. Berdasarkan hasil kalkulasi Gpower didapatkan total partisipan yang dibutuhkan minimal sebanyak 42 partisipan. Sebelum partisipan mengisi survei, partisipan diberikan informed consent yang bertujuan untuk mengetahui maksud serta tujuan dari penelitian ini.

\section{Pengukuran}

Penelitian ini mengukur kepemimpinan transformasional dengan mengadaptasi alat ukur Skala Kepemimpinan Transformasional yang diadaptasi dan dilakukan uji validitas serta reliabilitas oleh Farantia Dindy Devintasari (2016)dalam Bahasa Indonesia. Pernyataan disusun untuk menggambarkan gaya kepemimpinan transformsional secara umum atau secara keseluruhan terhadap interaksi antara karyawan dengan atasannya. Pernyataan berjumlah 11 aitem yang diukur menggunakan skala likert (14). Semakin tinggi skor, maka semakin tinggi tingkat gaya kepemimpinan transformasional.

Validitas alat ukur menggunakan metode Pearson Correlation dengan membandingkan nilai $r$ hitung dengan $r$ tabel sebesar 0,3494. Hasilnya didapatkan bahwa alat ukur kepemimpinan transformasional tersebut valid karena nilai $r$ hitung berkisar antara 0,475-0,789. Reliabilitas alat ukur menggunakan rumus koefisien Cronbach Alpha dengan hasil 0,810.

Iklim organisasi diukur menggunakan skala Organizational Climate Measure (OCM) yang telah diadaptasi oleh Yuhanisa (2019) dalam Bahasa Indonesia. Skala ini mengukur presepsi karyawan atas 
peraturan serta cara kerja pada organisasi dan interaksi antar anggota yang mengarah pada dukungan perilaku inovatif berdasarkan kuadran Open System Model. Pernyataan berjumlah 16 aitem dengan 12 aitem bersifat favorable dan 4 aitem bersifat unfavorable yang diukur dengan menggunakan skala likert (1-4). Semakin tinggi skornya, maka semakin menunjukkan persamaan persepsi yang dilihat dan dirasakan karyawan terhadap perusahaan. Validitas alat ukur menggunakan metode professional judgement dan uji reliabilitas menggunakan rumus koefisien Cronbach Alpha dengan hasil 0.858.

Perilaku kerja inovatif diukur menggunakan skala perilaku kerja inovatif yang telah diadaptasi oleh Devanny Kireina Dewi (2019)dalam Bahasa Indonesia. Skala ini mengukur tingkat perilaku inovatif seseorang dalam bekerja. Pernyataan berjumlah 9 aitem yang diukur menggunakan skala likert (1-7). Semakin tinggi skor individu, maka individu tersebut semakin inovatif. Validitas alat ukur menggunakan metode professional judgement dan uji reliabilitas menggunakan rumus koefisien Cronbach Alpha dengan hasil 0,922 .

\section{Analisis Data}

Teknik analisis yang digunakan adalah dilakukan uji regresi dengan multiple regression dan simple regression. Model ini dapat mengungkapkan persamaan garis yang diperlukan untuk memprediksi nilai variabel outcome atau Y ketika nilai prediktor atau variabel X diketahui (Navarro \& Foxcroft, 2019). Sebelum melakukan prosedur ini, terdapat beberapa uji asumsi yang harus dipenuhi, yaitu uji normalitas, uji linearitas, uji multikolinearitas, analisis residual, uji homokesdasdisitas dan deteksi outlier yang berpotensi mengganggu hasil penelitian. Semua prosedur ini menggunakan perangkat Jamovi 0.9.5.2.

Partisipan dalam penelitian ini sebanyak 73 karyawan yang bekerja di Industri Perhotelan Indonesia. Data yang diambil secara daring, berikut gambaran persebaran partisipan:

Berdasarkan informasi data demografis partisipan, partisipan pria berjumlah 43 (sebesar 58,9\%) dan partisipan wanita berjumlah 30 (sebesar 41,1\%). Berdasarkan kategori usia, partisipan terbanyak berada direntang usia 19-25 tahun (sebesar 54,8\%). Berdasarkan kategori Pendidikan, partisipan terbanyak berada dijenjang pendidikan SMA/SMK sebanyak 29 partisipan (sebesar 39,7\%). Berdasarkan kategori masa kerja, partisipan terbanyak bekerja selama kurang dari 2 tahun (sebesar $65,8 \%)$. Berdasarkan kategori jabatan, partisipan terbanyak merupakan resepsionis yaitu 18 partisipan (sebesar 24,7\%) dan berdasarkan kategori divisi/departemen partisipan terbanyak berasal dari departemen room division yaitu bagian front office sebanyak 25 partisipan (sebesar 34,2\%).Berdasarkan hasil analisis, pada setiap variabel jumlah data adalah 73, hal tersebut menandakan bahwa tidak ada data yang hilang. Nilai mean menunjukkan rata-rata respon yang diberikan oleh seluruh subjek serta sangat sensitif dengan nilai ekstrem. Variabilitas data dapat dilihat melalui nilai range yang diperoleh dari nilai minimum dan maksimum pada data (Navarro \& Foxcroft, 2019). Selain itu, standar deviasi juga dapat menunjukkan variabilitas data dengan cara menunjukkan jarak rata-rata antar skor dan nilai mean. Semakin besar nilai standar deviasi, maka semakin banyak variasi pada data (Neuman, 2007).

Nilai skewness menunjukkan indikasi simetri dari distribusi data. Sedangkan untuk nilai kurtosis memberikan informasi mengenai puncak distribusi data. Nilai skewness yang positif menujukkan bahwa data condong ke arah kiri, yang mana kebanyakan subjek memiliki nilai skor yang rendah, sebaliknya skewness negative menunjukkan data condong ke arah kanan, yang menandakan subjek memiliki nilai skor tinggi (Pallant, 2011). Nilai kurtosis yang positif menunjukkan bahwa distribusi data memuncak 
dan berkerumun di tengah. Sementara nilai kurtosis yang negatif menunjukkan distribusi data yang relatif rata (Pallant, 2011).

\section{Uji Asumsi}

Uji normalitas dilakukan bertujuan untuk mengetahui persebaran data, serta menentukan teknik analisis yang akan dilakukan. Uji normalitas data dilakukan melalui nilai skewness dan kurtosis (Pallant, 2011). Ketika nilai skewness menjauhi 1 dan mendekati 0, lalu nilai kurtosis menjauhi 2 dan mendekati 0 , maka data tersebut dapat dikatakan normal. Berdasarkan tabel 2, pada uji normalitas variabel kepemimpinan transformasional, iklim organisasi dan perilaku kerja inovatif memenuhi asumsi ini karena berdistribusi normal.

\section{HAS I L P E N EL I T I A N}

Penelitian ini bertujuan untuk mengidentifikasi adanya pengaruh kepemimpinan transformasional dan iklim organisasi terhadap perilaku kerja inovatif pada karyawan yang bekerja di hotel. Selain itu, pada penelitian ini juga ingin mengetahui dimensi manakah dari kuadran open system yang memiliki kontribusi paling besar yaitu dimensi innovation \& flexibility, outward focus dan reflexivity terhadap perilaku kerja inovatif. Guna mencapai tujuan-tujuan tersebut, penulis melakukan uji statistik yang mencakup multiple linear regression untuk menjawab ketiga rumusan masalah serta untuk melakukan uji terhadap hipotesis penelitian.

Hipotesis pertama yang ingin diuji adalah kepemimpinan transformasional berpengaruh terhadap perilaku kerja inovatif. Setelah dilakukan analisis regresi liner berganda, kepemimpinan transformasional dapat menggambarkan data $(F(1,71)=0.225$, nilai $\mathrm{p} \mathrm{0.636)}$ dengan koefisien determinasi sebesar $0.31 \%$. Hal ini menunjukkan bahwa kepemimpinan transformasional dapat menjelaskan variasi perilaku kerja inovatif sebesar $0.31 \%$, sedangkan sisanya dijelaskan oleh variabel lain yang tidak diteliti dalam penelitian ini. Pada model ini, nilai p yang dihasilkan adalah 0.636 yang berarti hasil yang diperoleh tidak signifikan. Sehingga dapat disimpulkan bahwa terdapat pengaruh yang tidak signifikan dari kepemimpinan transformasional terhadap perilaku kerja inovatif. Dengan hasil tersebut, maka $\mathrm{H}_{1}$ ditolak.

Kemudian untuk hipotesis yang kedua yang ingin diuji adalah pengaruh iklim organisasi terhadap perilaku kerja inovatif. Setelah dilakukan analisis regresi linear berganda, iklim organisasi dapat menggambarkan data $(F(1,71)=1.73$, nilai p 0.193) dengan koefisien determinasi sebesar $2.3 \%$. Hal ini menunjukkan bahwa iklim organisasi dapat menjelaskan variasi perilaku kerja inovatif sebesar $2.3 \%$, sedangkan sisanya dijelaskan oleh variabel lain yang tidak diteliti dalam penelitian ini. Pada model ini, nilai p yang dihasilkan adalah 0.193 yang berarti hasil yang diperoleh tidak signifikan. Sehingga dapat disimpulkan bahwa terdapat pengaruh yang tidak signifikan dari iklim organisasi terhadap perilaku kerja inovatif. Dengan hasil tersebut, maka $\mathrm{H}_{2}$ ditolak.

\section{I S K U S I}

Berdasarkan penjabaran diatas dapat dikaitkan dengan studi yang dilakukan oleh Arum (2018) yang mendapatkan hasil bahwa usia, tingkat Pendidikan dan lama bekerja dapat mempengaruhi perilaku kerja inovatif pada karyawan. Pada tingkat usia, rentang usia yang mampu menunjukkan perilaku kerja

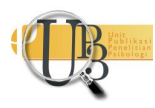


inovatif adalah pada usia 25-44 tahun, dimana pada usia tersebut individu mulai menstabilkan posisi pekerjaannya sehingga mampu mengekspresikan diri dan juga pada tahap ini individu mulai menunjukkan kinerja yang positif, produktif dan membangun relasi yang baik dengan rekan kerjanya. Sementara pada penelitian ini, 54,8\% responden berusia 19-25 tahun.

Kemudian untuk data demografis yang kedua yaitu level pendidikan. Pada penelitian Arum (2018) menyebutkan bahwa pengalaman seseorang dalam mengenyam pendidikan dapat memberikan banyak kesempatan untuk mengembangkan diri dan wawasan berpikirnya. Maka dari itu, semakin tinggi level pendidikan seseorang, maka secara umum meningkatkan kemampuan sehingga secara tidak langsung akan semakin besar memperoleh keterampilan kerja yang baru dan menampilkan perilaku kerja inovatif. Dari hasil penelitian ini, sebanyak 39,7\% responden yang mengisi level pendidikan terakhirnya adalah SMA/SMK.

Pada penelitian Arum (2018) menemukan bahwa semakin lama seorang individu bekerja maka akan semakin matang serta mampu memahami pekerjaannya, sehingga akan memungkinkan untuk melakukan inovasi. Berdasarkan penelitian Arum (2018) masa kerja merupakan salah satu hal yang dinilai memiliki relevansi untuk mengetahui performa kerja seseorang. Menurut Robbins \& Judge (2008) menyebutkan bahwa masa kerja dapat menggambarkan pengalaman kerja yang dimiliki oleh karyawan. Namun pada penelitian ini, sebanyak 65,8\% responden merupakan karyawan hotel yang bekerja masih kurang dari 2 tahun, bahkan ada banyak yang masih bekerja dalam kurun waktu kurang dari 1 tahun atau hanya hitungan bulan.

Data demografis yang terakhir adalah jabatan, dimana jabatan yang ada dalam penelitian ini tidak dibatasi, sehingga semua karyawan yang bekerja di hotel bisa menjadi responden penelitian, sementara tidak semua jabatan pekerjaan memerlukan perilaku inovatif untuk meningkatkan kualitas hotel tempat mereka bekerja. Dari beberapa penjabaran data demografis diatas, dapat disimpulkan bahwa kemungkinan faktor usia, level pendidikan, masa kerja serta jabatan dapat memengaruhi hasil penelitian ini sehingga didapatkan hasil yang tidak signifikan.

\section{S I M P U L A N}

Berdasarkan hasil analisis yang telah dilakukan, maka dapat disimpulkan bahwa tidak terdapat pengaruh yang signifikan antara kepemimpinan transformasional dan iklim organisasi terhadap perilaku kerja inovatif. Saran untuk penelitian selanjutnya adalah untuk menambahkan variabel lain seperti komitmen organisasi, modal psikologis, modal sosial dan karakteristik pekerjaan (Li \& Zheng, 2014). Kemudian, jika ingin melakukan penelitian lanjutan peneliti dapat mengontrol kriteria responden berdasarkan demografis usia, level pendidikan, masa kerja dan jabatan yang mengarah pada perilaku inovatif.

\section{U C AP A N TERIMAKASIH}

Penulis berterima kasih kepada responden dalam penelitian ini karena atas partisipasinya, penulis dapat menyelesaikan tulisan ini dengan baik. Semoga hasil penelitian ini dapat bermanfaat bagi penelitian selanjutnya maupun karyawan perhotelan. 


\section{DEKLARASI POTENSI TERJADINYA KONFLIK KEPENTINGAN}

Puspita Sandya Mahardika dan Dewi Syarifah tidak bekerja, menjadi konsultan, memiliki saham, atau menerima dana dari perusahaan atau organisasi manapun yang mungkin akan mengambil untung dari diterbitkannya naskah ini.

\section{PUSTAKA ACUAN}

Astuti, T; Tukijan; Sitawati, R. (2019). Pengaruh Kreativitas dan Perilaku Inovatif terhadap Kinerja karywan dengan Kepuasan Kerja sebagai Variabel Mediasi (Studi pada Hotel Pandanaran Semarang). Jurnal Ekonomi Manajemen dan Akuntansi, 54.

Azwar, S. (2004). Metode Penelitian. Yogyakarta: Liberty.

Bass, B. (1990). Bass and Stogdill's Handbook of Leadership: Theory, Research and Managerial Applications 3rd Ed. New York: Free Pass.

Cho, J., \& Danserau, F. (2010). Are Transformational Leaders Fair? A Multi-Level Study of Transformational Leadership, Justice Perceptions and Organizational Citizenship Behaviors. The Leadership Quarterly, 21(3) : 409-421.

Devintasari, F. D. (2016). Pengaruh Gaya Kepemimpinan Transformasional dan Transaksional terhadap Kinerja Karyawan dengan Quality of Work Life sebagai Variabel Moderasi (Studi Empiris pada Rumah Sakit di Kabupaten Temanggung).

Dewi, D. K. (2019). Hubungan antara Resiliensi dengan Perilaku Kerja Inovatif pada Karyawan Industri Pariwisata di Provinsi Bali.

Hargadon, A. (2015). How to Discover and Assess Opportunities for Business Model Innovation. Strategy and Leadership, 33-37.

Ikeda, K. \&. (2016). How Succesful Organizations Drive Innovation. Strategy and Leadership, 9-19.

Janssen, O. (2000). Job Demands, Perception of Effort Reward Fairness and Innovation Work Behavior. Journal of Occupantional and Organizational Psychology, 347-364.

Jong, J. d., \& Hartog, D. (2008). Innovation Work Behavior: Measurement and Validation. SCALES, 1-27.

Li, X., \& Zheng, Y. (2014). The Influential Factors of Employess Innovation Behavior and the Management Advices. Journal of Service SCiences and Management, 446-450.

Navarro, D., \& Foxcroft, D. (2019). Learning Statistics with Jamovi: A Tutor for Psychology Students and Other Beginners.

Neuman, W. L. (2007). Metode Penelitian Sosial: Pendekatan Kualitatif dan Kuantitatif. Jakarta: PT Indeks.

Nusair, N., Ababneh, R., \& Kyung Bae, Y. (2012). The Impact of Transformational Leadership Style on Innovation as Percieved by Public Employees in Jordan. International Journal of Commerce and Management, 182-201. 
Odoardi, C., Montani, F., Boudrias, J., \& Batittstelli, A. (2015). Linkin Managerial Practices and Leadesrhip Style to Innovative Work Behavior: The Role of Group and Psychologycal Processes. Leadership and Organization Development Journal, 36 (5) : 545-569.

Pallant, J. (2011). SPSS Survival Manual: A Step by Step Guide to Data Analysis Using the SPSS Program. Allen \& Unwin.

Patterson, M., West, M., Shackleton, V., Dawson, J., Lawthom, R., \& Maitlis, S. (2005). Validating the Organizational Climate Measure: Links to Managerial Practices, Productivity and Innovation. Journal of Organizational Behavior, 379-408.

Robbins, S. P., \& Judge, T. A. (2008). Perilaku Organisasi. Jakarta: Prihallindo.

Rogers, M. (1998). The Definition and Measurement of Innovation. Melbourne Institute of Applied Economic and Social Research, 1-27.

Webber, S. (2002). Leadership and Trust Facilitating Cross-functional Team Success. Journal of Mangement Development, 21 (3):201-204.

West, M., \& Farr, J. (1898). Innovation at Work: Psychological Prespectives Social Behavior.

Yuhanisa, M. (2019). Pengaruh Iklim Organisasi terhadap Perilaku Inovatif pada Karyawan Perusahaan E-Commerce. 